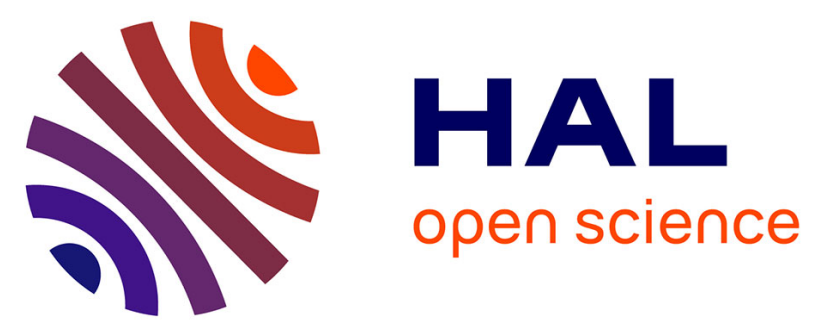

\title{
Water deficit stress induces different monoterpene and sesquiterpene emission changes in Mediterranean species. Relationship between terpene emissions and plant water potential
}

Elena Ormeno, J.P. Mevy, B. Vila, Anne Bousquet-Mélou, Stephane Greff, G. Bonin, Catherine Fernandez

\section{To cite this version:}

Elena Ormeno, J.P. Mevy, B. Vila, Anne Bousquet-Mélou, Stephane Greff, et al.. Water deficit stress induces different monoterpene and sesquiterpene emission changes in Mediterranean species. Relationship between terpene emissions and plant water potential. Chemosphere, 2007, 67 (2), pp.276 - 284. 10.1016/j.chemosphere.2006.10.029 . hal-01764557

\section{HAL Id: hal-01764557 \\ https://hal-amu.archives-ouvertes.fr/hal-01764557}

Submitted on 12 Apr 2018

HAL is a multi-disciplinary open access archive for the deposit and dissemination of scientific research documents, whether they are published or not. The documents may come from teaching and research institutions in France or abroad, or from public or private research centers.
L'archive ouverte pluridisciplinaire HAL, est destinée au dépôt et à la diffusion de documents scientifiques de niveau recherche, publiés ou non, émanant des établissements d'enseignement et de recherche français ou étrangers, des laboratoires publics ou privés. 


\title{
Water deficit stress induces different monoterpene and sesquiterpene emission changes in Mediterranean species. Relationship between terpene emissions and plant water potential
}

\author{
E. Ormeño *, J.P. Mévy, B. Vila, A. Bousquet-Mélou, S. Greff, G. Bonin, C. Fernandez \\ Equipe Ecologie Fonctionnelle, Institut Méditerranéen d'Ecologie et Paléoécologie (IMEP) - UMR 6116CNRS, Université de Provence, \\ Centre de St Jérôme, Case 421 Avenue Escadrille Normandie Niémen, 13397 Marseille, France
}

\begin{abstract}
The effects of water deficit stress and plant water potential $(\psi)$ on monoterpene and sesquiterpene leaf emissions from Rosmarinus officinalis, Pinus halepensis, Cistus albidus and Quercus coccifera were studied over 11 days of water withholding (from $t_{1}$ to $t_{11}$ ), after substrates had achieved their field capacity (control pots: $t_{0}$ ). Volatile compounds were sampled from the same twig per plant all throughout the study, using a dynamic bag enclosure system. Volatiles, collected in Tenax TA, were studied by means of GC-FID and GC-MS. Monoterpene emissions of water stressed plants $\left(t_{1}-t_{11}\right)$ were either similar to those of control seedlings $(R$. officinalis and $Q$. coccifera) o $\mathrm{r}$ higher ( $P$. halepensis and $C$. albidus). By contrast, sesquiterpene emissions were strongly reduced or inhibited after four days of water withholding, particularly for $R$. officinalis, thus altering terpene emission composition. Despite the positive effect of water stress on leaf monoterpene emissions of $P$. halepensis and $C$. albidus, the significant correlation between these emissions and $\psi$ showed a slow decrease of these emissions over long term water deficit periods. This contrasted with the rapid decline of sesquiterpene emissions of $R$. officinalis according to lower values of $\psi$. These results provide an overall picture of the different responses of monoterpene and sesquiterpene emissions to progressive water loss. They also reveal the utility of using $\psi$ for estimating some emission rates of some species according to drought conditions.
\end{abstract}

Keywords: BVOC; Terpenes; Drought; Mediterranean climate; Abiotic stress factors

\section{Introduction}

Terpenes released by plants constitute a major source of biogenic volatile organic compounds (BVOCs) in the atmosphere. These compounds play an important role in tropospheric photochemistry by modifying the ozone budget and by increasing the yield of Secondary Organic Aerosols (SOAs) (Guenther, 2002). Because of input inaccuracy, estimation of these secondary pollutant concentrations is still a process fraught with uncertainty. Therefore, better knowledge of factors causing alteration of these emissions

\footnotetext{
* Corresponding author. Tel.: +3349128 85 06; fax: +33491288707. E-mail address: elena.ormeno@univ-cezanne.fr (E. Ormeño).
}

could lead to more accurate BVOCs estimation. This is necessary for establishing more effective secondary pollutant control strategies.

Isoprene and monoterpenes are the only BVOCs considered in regional and global inventories and in models estimating plant emissions, since they are taken as representative of the most important reactive portion of total emissions released by vegetation at global scale (Guenther et al., 1995). However, some studies have demonstrated that other natural emissions, such as sesquiterpenes, also represent a substantial part of BVOCs (Hansen and Seufert, 1999; Maes and Debergh, 2003), and also modify the oxidative capacity of the atmosphere. Thus, sesquiterpenes play a more important role in SOAs formation, while monoterpenes are rather involved in tropospheric $\mathrm{O}_{3}$ 
production or destruction, depending on the availability of $\mathrm{NO} / \mathrm{NO}_{2}$ (Guenther, 2002).

The overall pattern and magnitude of BVOCs emissions vary markedly with vegetation cover and climate (Guenther et al., 1995). In the Mediterranean area, summer months are characterized by the highest annual temperatures and radiation levels which occur simultaneously with the most severe drought conditions. During this period, both emissions and secondary pollutant concentrations in the boundary layer reach their maximum concentrations (Tsigaridis and Kanakidou, 2002). Plant emissions are commonly dependent on temperature and radiation (Staudt and Bertin, 1998). Only these factors are taken into account when assessing the overall release of BVOCs from vegetation.

Soil water availability represents a major environmental constraint under Mediterranean conditions, and predictions suggest that the decline in total rainfall in the Mediterranean area will be drastic (Kattenburg et al., 1996). Under such conditions, it is likely that plants will experience increasing water deficit stress in their natural communities. Nonetheless, water stress is not yet considered as an input in plant emission models, maybe because it affects terpene emissions in different ways. Leaf emissions from plants under drought conditions are (i) reduced, due to restricted carbon acquisition (Staudt et al., 2002); (ii) inhibited (Llusià and Peñuelas, 1998) (iii) not modified (Peñuelas and Llusià, 1997) (iv) favoured (Sharkey and Loreto, 1993). In contrast to water stress, other abiotic stress factors, which also induce heat and/or oxidative burst, such as temperature, light (Staudt and Bertin, 1998) or $\mathrm{O}_{3}$ (Beauchamp et al., 2005), have been demonstrated to substantially favour temporary emissions from plants, in comparison with those of non-stressed plants. Plant emissions are thereby intended to protect leaves against these abiotic factors, but it is unclear whether plant emissions also protect leaves under water deficit. Studies focused on examining BVOCs dependency on this stress factor have mostly taken into account isoprene emissions (Pegoraro et al., 2004), while only a few reports have dealt with its impact on monoterpene emissions (Staudt et al., 2002), and particularly on sesquiterpene emissions (Hansen and Seufert, 1999).

The main goals of this study are (i) to investigate monoterpene and sesquiterpene emissions of four Mediterranean species during 11 days of water withholding (ii) to explore the relationship between these emissions and plant water potential $(\psi)$, in order to assess the possibility of using this physiological parameter to estimate terpene emission rates over a water withholding period.

\section{Materials and methods}

\subsection{Study species and experimental set-up}

Terpene emissions of Rosmarinus officinalis L., Pinus halepensis Mill. Cistus albidus L., and Quercus coccifera L., were studied. Q. coccifera is characterized by the lack of specialized terpene storage compartments in its leaves, which explains that its monoterpene emissions depend on both light and temperature as for isoprene emitters (Niinemets et al., 2002). The other species accumulate terpenes in specialized structures and their terpene emission is considered to be the consequence of terpene volatilization from these structures, which is temperature dependent (Llusià and Peñuelas, 2000).

Measurements were carried out from 7 to 18 June 2004 from 11:30 h to $16: 30 \mathrm{~h}$ (solar time). During this period progressive water loss was imposed. Eleven 3-year-old seedlings of each species were placed in clay pots (61) under natural conditions. Pots were filled with natural calcareous substrate. Six sample seedlings were used to study terpene emission dependency on water stress and to calculate soil water content, and five others were used to establish plant water status in parallel to terpene sampling.

Water deficit experimental design for all plants involved two phases. In the first phase, pots were introduced into a container full of water until field capacity was achieved. Firstly, pots were soaked, but evaporation rapidly impeded the constant contact between water and the superficial part of pots. Since the calcareous substrate used had a loam texture, optimum draining conditions were ensured, impeding anoxic risk. Field capacity was considered to be achieved when downward drainage flux from the confined substrates in pots was insignificant (Argiller et al., 1991). When percolation stops, the method proposed by Argiller et al. (1991) assumes that $\mathrm{pF}$ (water suction) is near 1.0, which is assessed to be the value at which substrates (without natural soil gradient) reach their field capacity. At this moment $\left(t_{0}\right)$, substrates contained maximum water content (Table $1)$. Thus, $t_{0}$-plants were treated as control plants. The second phase of the water deficit experimental design consisted in withholding water from $t_{0}$-plants during 11 days. Plant water status, soil water loss and terpene sampling were measured daily until the fourth day $\left(t_{1}, t_{2}, t_{3}\right.$, $\left.t_{4}\right)$ and then on the 7th $\left(t_{7}\right), 9$ th $\left(t_{9}\right)$ and 11th $\left(t_{11}\right)$ days. Using clay pots, instead of white and plastic pots, allowed progressive water loss over time and prevented strong increases of substrate temperature.

Plant water status was assessed through plant water potential $(\psi)$ and was measured from detached twigs with a pressure chamber (PMS instrument, Co., Oregon, USA), graduated from 0 to $70 \mathrm{kPa}$. Because this is a destructible measurement and $\psi$ was measured every day, plants used to calculate $\psi$ were different from those where emissions were sampled. For C. albidus, values of $\psi$ exceeded the measurement scale of the pressure chamber at $t_{9}$ and $t_{11}$. Thus, $\psi$ at these times was estimated from $\psi$ obtained at $t_{4}$ and $t_{7}:-7.1 \mathrm{MPa}$ at $t_{9}$ and $-8.0 \mathrm{MPa}$ at $t_{11}$. Substrate water content (SWC) was calculated by considering the difference between the weight of each pot each day and the weight of the same pot without any water content. SWC was then expressed in $\mathrm{cm}^{3} \mathrm{~kg}^{-1}$ (Table 1), by considering the substrate density, previously calculated $\left(1.13 \pm 0.05 \mathrm{~kg}^{-1}\right)$. 
Table 1

Environmental temperature, photosynthetically active radiation (PAR) and substrate water content (SWC), over the water deficit period

\begin{tabular}{|c|c|c|c|c|}
\hline Date $(\mathrm{dd} / \mathrm{mm} / \mathrm{yy})$ & Sampling time & Temperature $\left({ }^{\circ} \mathrm{C}\right)$ & $\operatorname{PAR}\left(\mu \mathrm{mol} \mathrm{m}{ }^{-2} \mathrm{~s}^{-1}\right)$ & $\operatorname{SWC}\left(\mathrm{cm}^{3} \mathrm{~kg}^{-1}\right)$ \\
\hline $7 / 06 / 2005$ & $t_{0}$ & $31.8 \pm 1.50$ & $1310 \pm 200$ & $210.0 \pm 1.4$ \\
\hline $8 / 06 / 2005$ & $t_{1}$ & $32.5 \pm 1.21$ & $1350 \pm 180$ & $132.9 \pm 1.2$ \\
\hline $9 / 06 / 2005$ & $t_{2}$ & $34.1 \pm 1.05$ & $1380 \pm 150$ & $89.5 \pm 0.9$ \\
\hline $10 / 06 / 2005$ & $t_{3}$ & $33.9 \pm 1.60$ & $1250 \pm 250$ & $58.5 \pm 1.6$ \\
\hline $11 / 06 / 2005$ & $t_{4}$ & $33.8 \pm 0.96$ & $1300 \pm 120$ & $51.3 \pm 0.4$ \\
\hline $14 / 06 / 2005$ & $t_{7}$ & $30.9 \pm 1.50$ & $1260 \pm 240$ & $32.2 \pm 0.3$ \\
\hline $16 / 06 / 2005$ & $t_{9}$ & $31.5 \pm 0.97$ & $1370 \pm 140$ & $27.3 \pm 0.3$ \\
\hline $18 / 06 / 2005$ & $t_{11}$ & $33.0 \pm 1.02$ & $1450 \pm 150$ & $18.7 \pm 0.2$ \\
\hline
\end{tabular}

Values are mean $\pm \mathrm{SE}$.

Internal bag and ambient temperatures (thermometer, WSC $888 \mathrm{H}$, Huger), PAR (Photosynthetically Active Radiation) (Portable photo system, plant and canopy transmission meter, Surechem ${ }^{\circledR}$, EMS-7 Model), relative air humidity (psychrometer, Jules Richard) and horizontal wind speed (Wind Speed Meter, WSC, 888H, Huger ${ }^{\circledR}$ ) were measured in parallel to terpene sampling. At all dates, wind was negligible $\left(0-2 \mathrm{~ms}^{-1}\right)$, relative air humidity was less than $30 \%$, and both ambient temperature and PAR remained similar (Table 1).

\subsection{Bag enclosure sampling system}

For terpene emission sampling, a dynamic bag enclosure system (following dynamic headspace sampling techniques described by Tholl et al., 2006), made of Teflon film (FEP), was carefully applied to enclose a single healthy twig per plant. The same twig of each plant was used throughout the study period, in order to eliminate branch to branch variability. Healthy state of leaves was set on the basis of a visual check. Sun and shade exposed leaves, as well as primary and secondary leaves, were considered. The emission rate obtained through this method is thus thought to be a fairly true representation of the mean emission rate of species studied. The system consisted of 16 bag enclosure systems. Each bag enclosure $(0.51)$ was designed with two air streams, inlet and outlet.

Before any sampling was taken, the air of each bag enclosure was renewed. For this purpose, each bag was continuously flushed with non-polluted air (Alphagaz, 99.99\% purity), through a Tygon tube (Tygon ${ }^{\circledR}$ Fuel and lubricant tubing, i.d: $8 \mathrm{~mm}$ ), specially designed for hydrocarbure transport. Inflowing air $(\mathrm{Qe})$ was precisely measured with a digital mass-flow controller (Aalborg ${ }^{\circledR}$ CFC17, $0-500 \mathrm{ml}$ ). Qe was $100 \pm 30 \mathrm{ml} \mathrm{min}^{-1}$ and was maintained during $15 \mathrm{~min}$. After air renewal, terpene sampling took place, while inflowing air continued. The outgoing terpenes from each bag enclosure were collected on glass sorbent tubes filled with preconditioned Tenax TA (Varian ${ }^{\circledR}, 20-35$ mesh, $150 \mathrm{mg}, 1: 160 \mathrm{~mm}$, o.d: $5 \mathrm{~mm}$, i.d: $3 \mathrm{~mm}$ ), using a pumping system (Edwards $\left.{ }^{\circledR}\right)$, placed downstream from the adsorbent tubes. One Tenax TA per bag enclosure was used. Outflowing air (Qs) from each bag enclosure was precisely measured with a bubble flow meter
(0-280 ml min ${ }^{-1}$, GPE Meterate 314-140/084), placed immediately after each Tenax. Flow meters were specially designed to allow connection to a tube. This was necessary, since each flow meter was linked to the pump through a reinforced flexible and antioxidant PVC tube (i.d. $0.8 \mathrm{~mm}$ ). Terpene sampling took place during $10 \mathrm{~min}$ at $\mathrm{Qs}=80 \pm 30 \mathrm{ml} \mathrm{min}^{-1}$. The sampled air volume was calculated in order to optimise the signal/threshold ratio without exceeding the breakthrough volumes of each compound. When sampling was finished, Tenax TA were immediately placed in a fridge at $+4{ }^{\circ} \mathrm{C}$ until being stored at $-20{ }^{\circ} \mathrm{C}$ in the laboratory. Although if 16 bag enclosures were prepared, only 14 were directly used to sample terpene emissions, since one of them was always allocated to a blank, with no twig in the gas exchange system, and another bag enclosure was used for measurement of air temperature inside the enclosure.

Qe applied during terpene sampling, which was the same as that used at the air renewing phase, was higher than Qs, in order to reduce the difference between leaf and internal bag temperatures. This also visibly reduced plant transpiration and allowed the air bag to be slightly over-pressurized, preventing leaf contact with the Teflon film and outside ambient air penetration. Transpiration inside the enclosure system is a phenomenon, which cannot easily be prevented in this type of measurement and occurs because branch temperature in the enclosure shows higher temperatures than the outside branch. Transpiration was relatively slight during sampling because sampling time was relatively short (10 $\mathrm{min})$ and inflowing air into each bag enclosure was relatively higher than outflowing air.

When terpene sampling was finished (at the end of the 11th day), each twig was cut off. Then leaves were lyophilized (Lyovac GT2 ${ }^{\circledR}$ ) in order to express emission rates on the basis of dry matter (DM). Total foliage DM per twig ranged from 2 to $4 \mathrm{~g}$.

\subsection{Terpene analyses and standard emission $\left(E_{S}\right)$ calculation}

Tenax TA with adsorbed terpenes $(n=192)$ were analyzed randomly (instead of chronologically) immediately after sampling. They were analyzed by a gas chromatography system (GC) fitted with a Flame ionization detector 
(FID) $\left(\mathrm{HP}^{\circledR} 5890\right.$ series II). Prior to thermaldesorption, a preflush phase was run $\left(3 \mathrm{~min}, 10 \mathrm{ml} \mathrm{min}^{-1}, 60^{\circ} \mathrm{C}\right)$ to allow humidity in the Tenax to be evacuated. Then, thermaldesorption (Thermal Desorption Cold Trap injector, Var$\operatorname{ian}^{\circledR}$, CP4020-TCT, model) was carried out under nitrogen

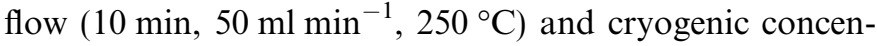
tration in a silica capillary trap, cooled with liquid nitrogen at $-100{ }^{\circ} \mathrm{C}$. Compounds were then separated in the nonpolar chromatographic column (Ultra 2, $50 \mathrm{~m} \times 0.2 \mathrm{~mm} \times$ $0.25 \mu \mathrm{m}$ ) through a temperature programme from $60{ }^{\circ} \mathrm{C}$ to $220^{\circ} \mathrm{C}$, at a rate of $3{ }^{\circ} \mathrm{C} \mathrm{min}{ }^{-1}$, then $220^{\circ} \mathrm{C}$ (isothermal) for $5 \mathrm{~min}$.

The identity of peaks was mainly verified by matching the retention time of each compound with that of commercial standards (Sigma-Aldrich). Also, the retention index of each compound was calculated and compared with those found in the literature. In a few cases, when standards were not available, peak identification was achieved by injection of previously extracted terpenes from each species, in Tenax TA. The identity of these compounds was determined through a GC-MS (gas chromatography, HewlettPackard GC6890 ${ }^{\circledR}$ ) coupled to a mass selective detector (MSD, HP 5973N).

Monoterpene, sesquiterpene and total standard emissions ( $E_{\mathrm{SM}}, E_{\mathrm{SS}}, E_{\mathrm{ST}}$, respectively) of $R$. officinalis, P. halepensis and $C$. albidus were calculated by the algorithm proposed by Tingey et al. (1980) (standardization to $30^{\circ} \mathrm{C}$ temperature) since temperature is the main environmental parameter controlling emissions of storing species. $E_{\mathrm{SM}}, E_{\mathrm{SS}}, E_{\mathrm{ST}}$ of $Q$. coccifera were calculated following Guenther et al. (1995) algorithm (standardization to $30^{\circ} \mathrm{C}$ and $1000 \mu \mathrm{mol}$ $\mathrm{m}^{-2} \mathrm{~s}^{-1}$ ), since terpene emissions of this non-storing Mediterranean oak are currently considered to be temperature and light dependent (Niinemets et al., 2002). Bag air temperature instead of leaf temperature was measured through sampling, as shown in other studies (e.g., Hansen et al., 1997; Llusià and Peñuelas, 2000; Sabillon and Cremades, 2001). This limitation might potentially increase the error in the computed emission factor. However, this procedure is partly justified since (i) emissions sampled in this study came from a group of leaves instead of single leaves (ii) the difference between the bag air temperature and that of the leaf surface was reduced since relatively high rates of inflowing air were applied through the bag enclosure system (iii) some studies have evidenced that the difference between leaf and enclosure air temperatures is rarely higher than $1{ }^{\circ} \mathrm{C}$ (in Sabillon and Cremades, 2001) (iv) Arey et al. (1995) underlined that for purposes of scaling-up to an emissions inventory, the ambient light levels and the temperature within the enclosure, rather than individual leaf measurements of temperature and PAR, are more appropriate.

\subsection{Statistical analyses}

A pair comparison test (mean comparison) was applied to compare terpene emissions over the water withholding period (from $t_{1}$ to $t_{11}$ ) with those from $t_{0}$ plants (control plants). The test was applied after normalizing emissions by log-transformation. Dependency of $E_{\mathrm{SM}}, E_{\mathrm{SS}}$ and $E_{\mathrm{ST}}$ on $\psi$ was analyzed using non-linear regression analyses. Analyses were conducted with the Statgraphics ${ }^{\circledR}$, version 4.1 .

\section{Results and discussion}

\section{1. $E_{S M}$ of P. halepensis and C. albidus throughout the water stress period}

This study shows that water stress has a positive effect on monoterpene emissions of $P$. halepensis and C. albidus, since emissions from $t_{1}$ to $t_{11}$ are significantly higher than those obtained for control plants (at $t_{0}$ ) (Fig. 1; $p<0.05$ ). However, while $E_{\mathrm{SM}}$ of $P$. halepensis increased slightly from the first day of water withholding, $E_{\mathrm{SM}}$ of $C$. albidus mainly increased after a week of water deficit. For both species, $E_{\mathrm{SM}}$ is significantly correlated to $\psi$ (S-Curve model, Fig. $2 ; p<0.05$ ). This model shows that $E_{\mathrm{SM}}$ (i) increased in a first phase (from $t_{1}$ to $t_{7}$ ) (ii) then it slightly decreased in a second phase (from $t_{7}$ to $t_{11}$ ), when values of $\psi$ are very low, indicating severe water deficit.

Increases in $E_{\mathrm{SM}}$ of $C$. albidus and P. halepensis in the first phase of water deficit (Fig. 1), contrast with data provided by Llusià and Peñuelas (1998). These authors showed that terpene emissions of these two species were inhibited after seven days of water withholding. Since the volume of the pots used in their study was more than 3-fold smaller than that used here, their results could suggest that water loss in their work was more rapid than that shown in this study. Nowadays, Yani et al. (1993) (leaf monoterpenes), Sharkey and Loreto (1993) (leaf isoprene) and Vallat et al., 2005 (wood monoterpenes) have shown a positive effect of drought in plant isoprenoid emissions, before they decreased drastically when water deficit was severe. Sharkey and Loreto (1993) provided these data, despite the fact that isoprene emission was highly dependent on the photosynthetic activity. They concluded that isoprene responded in this way since normally $2 \%$ of the carbon fixed by photosynthesis was re-emitted as isoprene, while under water stress, over $50 \%$ of the photosynthetically fixed carbon was emitted by kudzu leaves as isoprene, suggesting that this phenomenon could also occur for monoterpenes.

Some other findings could elucidate why monoterpene emissions of $P$. halepensis and $C$. albidus were not reduced by water withholding in this study: (i) contrary to isoprene, the cuticle may be permeable to monoterpenes (Schmid et al., 1992), allowing monoterpene emissions to be maintained during drought conditions when stomata closure occurs (Pegoraro et al., 2004), (ii) because plants growing under water-limited conditions are likely to loose less water and thus have less evaporation cooling, severe water deficit conditions will be accompanied by increases in temperature, which favour in turn terpene emissions (Staudt and Bertin, 1998), (iii) the ability to use alternative carbon sources, as opposed to recently assimilated photosynthate, 

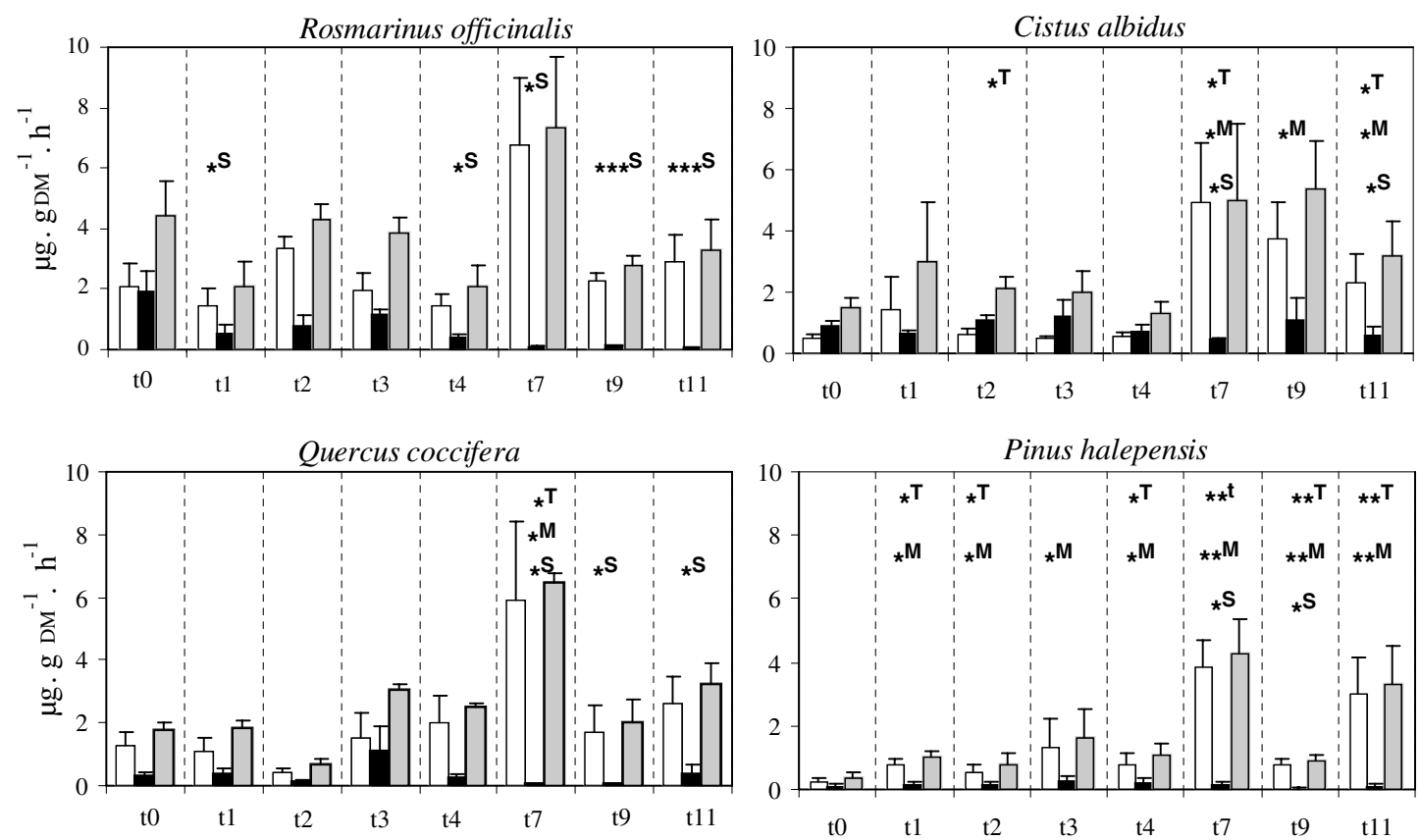

Monoterpene standard emissions $\left(\mathrm{E}_{\mathrm{SM}}\right)$

Sesquiterpene standard emissions $\left(\mathrm{E}_{\mathrm{SS}}\right)$

Total standard emissions $\left(\mathrm{E}_{\mathrm{ST}}\right)$

Fig. 1. Paired sample comparison between standard emissions at $t_{0}$ (when substrates had achieved field capacity) and standard emissions from $t_{1}$ to $t_{11}$ (water stressed plants). Monoterpene, sesquiterpene and total standard emissions ( $E_{S M}, E_{\mathrm{SS}}$ and $E_{\mathrm{ST}}$, respectively) of $R$. officinalis, P. halepensis, $C$. albidus and $Q$. coccifera are shown separately. Data are mean values $\pm \operatorname{SE}(n=6) .{ }^{*}: 0.01<p<0.05 ;{ }^{* *}: 0.001<p<0.01 ;{ }^{* * *} p<0.001 .{ }^{*} M$, ${ }^{*} S$ and ${ }^{*} T$ indicate if $p$ value corresponds to $E_{S M}, E_{\mathrm{SS}}$ and $E_{\mathrm{ST}}$, respectively.

for isoprene production, seems to be important as plants experience routinely photosynthetic depression in response to environmental stress (Funk et al., 2004). Probably, this alternative carbon sources could also contribute to maintain production of monoterpenes under severe photosynthetic limitation, preventing these isoprenoids from being reduced. (iv) $P$. halepensis and C. albidus possess specific storage compartments for monoterpenes. These reservoirs allow emission maintenance, even if at the whole-plant level the effect of water deficit stress is usually perceived as a decrease in photosynthesis (Llusià and Peñuelas, 1998; Staudt et al., 2002; Pegoraro et al., 2004), which provides the energy for terpene production. The lack of control of light on monoterpene emissions of some storing species was firstly suggested by Tingey et al. (1980). These authors described a temperature dependent monoterpene efflux from leaves, assuming that monoterpenes were emitted primarily from storage pools in such a way that their emission rates were uncoupled from the synthesis rates. Therefore, increases in leaf monoterpene emissions of $P$. halepensis and C. albidus could also be due to the fact that monoterpene accumulation within leaves is favoured during drought periods (Turtola et al., 2003). According to these authors, plants produce high terpene concentrations under environmental stress conditions because of a low allocation of carbon to the growth, suggesting a trade-off between growth and defence. This is consistent with predictions of the carbon/nutrient balance (CNB) (Bryan et al., 1983 ) and the growth differentiation balance (GDB)
(Lorio, 1986) hypothesis. Regarding C. albidus, it should be stressed that considering the existence of these structures as an explanatory factor of its monoterpene emission increase under drought conditions, could be confusing since only sesquiterpenes are stored in the leaves of this species (Llusià and Peñuelas, 2000).

Because plant transpiration favours monoterpene emissions (e.g. P. halepensis, Simon et al., 2005), it was investigated here whether increases in monoterpene emissions of $P$. halepensis and C. albidus were caused by this phenomenon. This possibility is ruled out since $P$. halepensis (Inclan et al., 1998) and C. albidus (Werner et al., 1999) are typically considered to minimize water loss by reducing leaf transpiration when they posses lower water content. Thus, if transpiration had favoured their monoterpene emissions, they should have increased at the beginning of the water stress period, when plants are assumed to exhibit a higher transpiration rate, whereas the opposite reaction was in fact observed. Hence, monoterpene emission increase under water deficit stress may be due to other physiological processes than that of transpiration.

In the second phase of water withholding $\left(t_{7}-t_{11}\right)$, this study showed that $E_{\mathrm{SM}}$ of $P$. halepensis and $C$. albidus declined slowly (Fig. 2), while Yani et al. (1993) showed a dramatic decline of some monoterpene emissions from wood of Cupressus sempervirens, a terpene storing species, after a long drought period. The fact that $E_{\mathrm{SM}}$ declined slowly can be explained by a progressive depletion of terpene synthesis in response to a prolonged water deficit, 

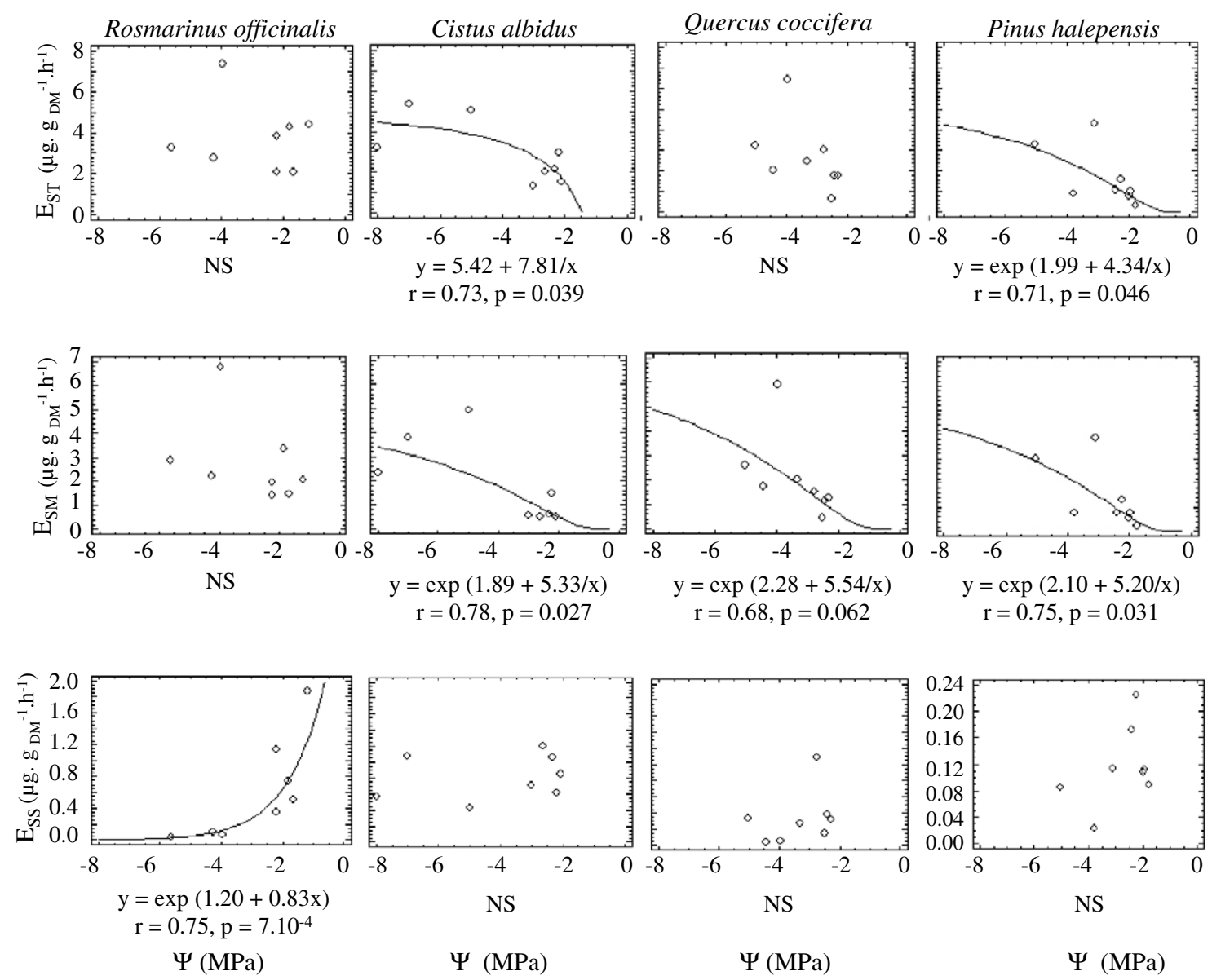

Fig. 2. Non-linear regression analyses between mean water potential $(\psi)$ and total emission factor $\left(E_{\mathrm{ST}}\right)$, monoterpene emission factor $\left(E_{\mathrm{SM}}\right)$ and sesquiterpene emission factor $\left(E_{\mathrm{SS}}\right)$ of $R$. officinalis, $C$. albidus, $Q$. coccifera and $P$. halepensis over 11 days of water withholding $(n=8)$. $(r$ : correlation coefficient, $p$ : relationship significance, NS: not significant). Measurements of $\psi$ were carried out in parallel to emission measurements, so between 11:30 h and 16:00 $\mathrm{h}$ (solar time) and from different seedlings (see text).

leading to a lack of photosynthetic substrate. Furthermore, it has recently been shown for $P$. halepensis that (i) a considerable fraction of its monoterpene emissions is directly linked to its photosynthetic activity (Simon et al., 2005) (ii) its photosynthetic activity only declines after seven days of water stress (Inclan et al., 1998).

\section{2. $E_{S M}$ of $R$. officinalis and $Q$. coccifera throughout the water stress period}

In contrast to $P$. halepensis and $C$. albidus, $E_{\mathrm{SM}}$ of $R$. officinalis did not change over the study period, either when emissions from $t_{1}$ to $t_{11}$ are compared to those at $t_{0}$ $(p>0.05$; Fig. 1$)$, or when emissions are correlated to $\psi$ $(p>0.05$; Fig. 2). Peñuelas and Llusià (1997) also showed that monoterpene emissions of $R$. officinalis remained stable under water deficit conditions. An explanation for this response could be that terpene accumulation in its specialized structures is triggered under water deficit (Delfine et al., 2005). However, despite the existence of pool tissues in leaves of both, $R$. officinalis and $P$. halepensis, this study shows that their monoterpene emissions are affected differ- ently by water deficit. This might be due to the lack of dependency on photosynthesis of rosemary terpene emissions (Hansen et al., 1997), while a fraction of terpenes released by $P$. halepensis is dependent on its photosynthetic activity (Simon et al., 2005).

Like $R$. officinalis, $E_{S M}$ of $Q$. coccifera remained stable throughout the water deficit period, despite the absence of storage organs in leaves of this species. Thus, $E_{\mathrm{SM}}$ from $t_{1}$ to $t_{11}$ (except at $\left.t_{7}\right)$ was similar to $E_{\mathrm{SM}}$ at $t_{0}(p>0.05$; Fig. 1) and $E_{\mathrm{SM}}$ was not significantly correlated to $\psi$ $(p>0.05$; Fig. 2). Results reported by Llusià and Peñuelas (1998) are not consistent with results found here. These authors found that monoterpene emissions of $Q$. coccifera were inhibited after a week of water withholding. These inconsistencies may be explained by different experimental protocols (e.g. pot volume), as explained previously. Findings in the study carried out by Pegoraro et al. (2004) for isoprene emissions of Quercus virginiana Mill. are partially consistent with those obtained here for $Q$. coccifera. Comparing isoprene emissions of $Q$. virginiana to monoterpene emissions of $Q$. coccifera is appropriate because $Q$. coccifera does not posses specific terpene storage structures in its 
leaves. This implies that its monoterpene emissions are directly dependent on the photosynthetic activity, like isoprene (Guenther et al., 1995). Pegoraro et al. (2004) showed that isoprene emissions remained stable during the first eight days of water withholding. However, in contrast to this study, isoprene emissions declined thereafter and were significantly correlated to $\psi$. The authors attributed these results to an increase in the fraction of $\mathrm{CO}_{2}$ fixed by the plant for synthesising BVOCs. The response observed here for $Q$. coccifera could be elucidated by the fact that monoterpene emissions are less sensitive to water stress than photosynthetic activity (Bertin and Staudt, 1996), partly because the lack of terpene storage structures may be compensated for by an increase in the internal BVOCs concentrations in both lipid and aqueous phases of leaves (Niinemets et al., 2004).
Therefore, the existence of these temporary storage structures is likely to introduce time-lags in the responses of emission rates of non-stored monoterpenes (Staudt and Bertin, 1998). Moreover, Q. coccifera is characterized by watersaving for long drought periods and is especially resistant to drought (Vilagrosa et al., 2003). Thus, when $\psi$ of this species ranged between -0.1 and $5 \mathrm{MPa}$, as it did in this study, its leaves did not show any visible injury (Vilagrosa et al., 2003).

\section{3. $E_{S S}$ changes during the water stress period}

All species show lower $E_{\mathrm{SS}}$ in water stressed plants than in control plants ( $p<0.05$; Fig. 1, Table 2 ). $E_{\mathrm{SS}}$ of all species is especially restricted from the fourth day of water

Table 2

Contribution (\%) of major monoterpenes (normal style) and sesquiterpenes (italic letters) to total emissions of R. officinalis, P. halepensis, C. albidus and Q. coccifera during 11 days of water withholding

\begin{tabular}{|c|c|c|c|c|c|c|c|c|}
\hline & $t_{0}$ & $t_{1}$ & $t_{2}$ & $t_{3}$ & $t_{4}$ & $t_{7}$ & $t_{9}$ & $t_{11}$ \\
\hline \multicolumn{9}{|l|}{ Rosmarinus officinalis } \\
\hline$\alpha$-pinene & $7.6 \pm 2.4$ & $31.6 \pm 12.2$ & $38.9 \pm 18.2$ & $15.0 \pm 7.3$ & $19.3 \pm 6.0$ & $52.0 \pm 21.7$ & $44.8 \pm 14.3$ & $59.9 \pm 20.4$ \\
\hline Sabinene & $3.0 \pm 1.1$ & $13.5 \pm 5.7$ & $7.2 \pm 3.2$ & $5.1 \pm 2.3$ & $6.6 \pm 3.3$ & $6.1 \pm 3.1$ & $4.9 \pm 1.6$ & $5.7 \pm 2.1$ \\
\hline$\beta$-myrcene & $3.6 \pm 1.1$ & $4.9 \pm 2.8$ & $16.9 \pm 7.6$ & $2.5 \pm 1.4$ & $8.1 \pm 4.2$ & $18.4 \pm 9.3$ & $10.1 \pm 3.4$ & $9.4 \pm 3.1$ \\
\hline 1.8-cineole & $20.6 \pm 10.7$ & $4.3 \pm 2.2$ & $0.4 \pm 0.2$ & $5.4 \pm 2.9$ & $7.2 \pm 3.9$ & $1.6 \pm 0.8$ & $3.9 \pm 1.4$ & $2.4 \pm 0.5$ \\
\hline Cis linalool oxide & $7.4 \pm 2.6$ & $5.4 \pm 1.4$ & $2.2 \pm 0.8$ & $6.4 \pm 3.6$ & $11.0 \pm 3.4$ & $3.9 \pm 0.8$ & $5.8 \pm 1.7$ & $3.3 \pm 1.1$ \\
\hline Allo-aromadendrene & $5.8 \pm 2.2$ & $4.0 \pm 2.1$ & $3.4 \pm 1.1$ & $6.6 \pm 1.7$ & $3.7 \pm 2.4$ & - & - & - \\
\hline 4-germacrene & $6.8 \pm 2.6$ & $5.2 \pm 1.7$ & $4.3 \pm 2.8$ & $6.6 \pm 1.7$ & $6.7 \pm 3.2$ & - & - & - \\
\hline$\alpha$-zingiberene & $7.13 \pm 3.5$ & $5.1 \pm 5.1$ & $0.71 \pm 0.5$ & $2.7 \pm 1.5$ & $<1$ & - & - & - \\
\hline A-cadinene & $7.5 \pm 2.4$ & $3.7 \pm 1.6$ & $6.2 \pm 2.8$ & $11.5 \pm 2.2$ & $5.3 \pm 1.2$ & - & - & - \\
\hline \multicolumn{9}{|l|}{ Pinus halepensis } \\
\hline$\alpha$-pinene & $30.8 \pm 10.6$ & $39.2 \pm 11.2$ & $34.5 \pm 15.5$ & $37.8 \pm 19.4$ & $36.4 \pm 14.6$ & $60.0 \pm 14.3$ & $57.2 \pm 13.1$ & $52.0 \pm 19.5$ \\
\hline$\Delta^{3}$-carene & $21.1 \pm 12.1$ & $19.6 \pm 8.7$ & $25.4 \pm 13.5$ & $26.8 \pm 16.2$ & $21.2 \pm 10.8$ & $6.4 \pm 1.3$ & $7.4 \pm 0.8$ & $15.5 \pm 7.0$ \\
\hline$\beta$-pinene & $0.8 \pm 0.4$ & $4.7 \pm 2.3$ & $5.6 \pm 3.1$ & $5.2 \pm 2.5$ & $2.9 \pm 1.0$ & $2.7 \pm 0.6$ & $2.3 \pm 0.7$ & $2.8 \pm 1.4$ \\
\hline$\beta$-myrcene & $0.8 \pm 0.3$ & $4.3 \pm 2.7$ & $6.3 \pm 3.0$ & $4.4 \pm 2.1$ & $4.1 \pm 2.0$ & $12.2 \pm 3.7$ & $9.8 \pm 2.2$ & $13.8 \pm 6.5$ \\
\hline Linalool & $7.7 \pm 4.3$ & $8.7 \pm 1.7$ & $5.1 \pm 1.7$ & $3.4 \pm 0.8$ & $4.8 \pm 1.3$ & $2.2 \pm 0.8$ & $1.0 \pm 0.4$ & $1.3 \pm 0.3$ \\
\hline$\alpha$-caryophyllene & $5.3 \pm 2.4$ & $2.8 \pm 1.4$ & $0.9 \pm 0.3$ & $0.5 \pm 0.2$ & $4.7 \pm 1.4$ & - & - & - \\
\hline Allo-aromadendrene & $9.8 \pm 4.3$ & $3.0 \pm 0.5$ & $2.3 \pm 0.7$ & $3.2 \pm 0.6$ & $5.6 \pm 1.8$ & - & - & - \\
\hline 4-germacrene & $6.5 \pm 3.3$ & $2.2 \pm 0.8$ & $3.3 \pm 1.2$ & $1.9 \pm 0.4$ & - & - & - & - \\
\hline$\Delta$-cadinene & $7.7 \pm 3.7$ & $5.1 \pm 0.7$ & $4.9 \pm 1.5$ & $1.3 \pm 0.5$ & $8.4 \pm 3.0$ & - & - & - \\
\hline \multicolumn{9}{|l|}{ Cistus albidus } \\
\hline$\alpha$-pinene & $8.0 \pm 2.6$ & $6.7 \pm 3.6$ & $6.2 \pm 2.5$ & $2.6 \pm 1.4$ & $16.5 \pm 7.2$ & $61.5 \pm 21.2$ & $37.2 \pm 9.5$ & $53.6 \pm 22.8$ \\
\hline$\beta$-pinene & $8.9 \pm 4.0$ & $45.2 \pm 23.6$ & $8.8 \pm 5.3$ & $5.0 \pm 2.0$ & $3.4 \pm 1.3$ & $5.3 \pm 2.4$ & $4.2 \pm 1.7$ & $1.8 \pm 0.7$ \\
\hline Cis linalool oxide & $10.2 \pm 4.5$ & $10.4 \pm 5.5$ & $10.0 \pm 3.2$ & $10.6 \pm 3.3$ & $9.2 \pm 4.2$ & $2.4 \pm 0.8$ & $3.5 \pm 1.1$ & $7.9 \pm 2.9$ \\
\hline Linalool & $8.7 \pm 2.8$ & $4.8 \pm 2.1$ & $9.1 \pm 2.8$ & $6.6 \pm 2.7$ & $11.0 \pm 4.4$ & $2.2 \pm 0.9$ & $<1$ & $2.6 \pm 0.7$ \\
\hline$\beta$-bourbonene & $7.0 \pm 3.1$ & $1.3 \pm 0.6$ & $4.7 \pm 2.1$ & $9.4 \pm 4.2$ & $3.3 \pm 1.8$ & - & - & - \\
\hline$\beta$-caryophyllene & $6.8 \pm 2.1$ & $1.4 \pm 0.5$ & $5.6 \pm 3.3$ & $5.4 \pm 3.0$ & $6.9 \pm 1.6$ & $2.6 \pm 1.8$ & $4.0 \pm 2.2$ & $6.3 \pm 3.0$ \\
\hline$\alpha$-caryophyllene & $0.7 \pm 0.3$ & $1.4 \pm 0.8$ & $3.0 \pm 1.3$ & $5.3 \pm 2.5$ & $4.7 \pm 3.0$ & $0.6 \pm 0.6$ & $1.4 \pm 0.8$ & $0.8 \pm 0.6$ \\
\hline Allo-aromadendrene & $6.7 \pm 2.4$ & $5.1 \pm 1.3$ & $8.2 \pm 2.1$ & $5.9 \pm 1.5$ & $7.9 \pm 2.6$ & $<1$ & $2.8 \pm 1.7$ & $1.4 \pm 0.5$ \\
\hline$\Delta$-germacrene & $6.6 \pm 2.3$ & $4.3 \pm 1.7$ & $5.7 \pm 2.4$ & $2.8 \pm 1.0$ & $7.0 \pm 3.9$ & - & - & $<1$ \\
\hline AR-curcumene & $10.7 \pm 4.5$ & $1.6 \pm 0.8$ & $11.0 \pm 2.6$ & $13.5 \pm 8.5$ & $8.8 \pm 2.8$ & $<1$ & $6.5 \pm 3.8$ & $4.8 \pm 2.6$ \\
\hline$\alpha$-zingiberene & $11.1 \pm 4.5$ & $4.1 \pm 1.5$ & $12.4 \pm 3.3$ & $18.3 \pm 8.6$ & $9.0 \pm 4.1$ & $<1$ & $<1$ & $<1$ \\
\hline \multicolumn{9}{|l|}{ Quercus coccifera } \\
\hline$\alpha$-pinene & $9.6 \pm 3.3$ & $22.8 \pm 8.1$ & $17.9 \pm 6.4$ & $20.2 \pm 10.3$ & $33.2 \pm 16.7$ & $74.6 \pm 32.6$ & $53.4 \pm 24.6$ & $65.1 \pm 20.7$ \\
\hline Sabinene & $6.4 \pm 2.8$ & $5.3 \pm 2.4$ & $3.3 \pm 1.3$ & $11.1 \pm 5.2$ & $6.6 \pm 3.5$ & $5.3 \pm 2.5$ & $6.7 \pm 3.4$ & $5.5 \pm 1.8$ \\
\hline$\beta$-pinene & $3.4 \pm 1.6$ & $13.5 \pm 8.2$ & $7.9 \pm 3.4$ & $13.8 \pm 8.2$ & $21.5 \pm 12.2$ & $2.5 \pm 0.8$ & $9.3 \pm 4.6$ & $2.5 \pm 0.8$ \\
\hline$\beta$-myrcene & $24.3 \pm 11.7$ & $15.1 \pm 7.2$ & $24.7 \pm 12.6$ & $14.5 \pm 7.1$ & $15.6 \pm 8.0$ & $8.7 \pm 3.2$ & $12.9 \pm 5.1$ & $8.8 \pm 3.0$ \\
\hline Allo-aromadendrene & $5.4 \pm 2.3$ & $3.7 \pm 1.7$ & $5.3 \pm 2.6$ & $2.4 \pm 0.8$ & $2.9 \pm 1.2$ & - & - & $5.0 \pm 3.0$ \\
\hline$\Delta$-germacrene & $4.5 \pm 1.6$ & $6.3 \pm 3.2$ & $5.6 \pm 2.1$ & $6.2 \pm 4.3$ & $2.9 \pm 0.9$ & - & $<1$ & $2.5 \pm 1.2$ \\
\hline$\Delta$-cadinene & $8.9 \pm 2.6$ & $9.3 \pm 5.0$ & $5.7 \pm 1.3$ & $3.4 \pm 1.7$ & $4.1 \pm 1.2$ & - & - & - \\
\hline
\end{tabular}

$\mathrm{X}$ : undetected compound.

Values are mean $\pm \mathrm{SE}, n=6$. 
withholding. Thus, while major sesquiterpenes contribute between $10 \%$ and $40 \%$ of total emissions from $t_{0}$ to $t_{4}$, thereafter they are inhibited or represent negligible percentages of total emissions (Table 2). Consequently, water stress induces a shift in terpene composition when water withholding exceeds four days. Only $E_{\mathrm{SS}}$ of $R$. officinalis decreases from the first day $\left(t_{1}\right)$ of water withholding. This probably explains why only $E_{\mathrm{SS}}$ of this species is significantly correlated to $\psi$ (exponential model, $p<0.05$; Fig. 2). This model shows a rapid decline of $E_{\mathrm{SS}}$ with increasing water loss.

Results shown by Hansen and Seufert (1999) for Citrus sinensis $\mathrm{L}$. are consistent with those obtained in this study for all species except for $R$. officinalis. According to their study, $E_{\mathrm{SS}}$ ( $\beta$-caryophyllene only) was strongly reduced under severe water deficit, while it remained unchangeable under mild water stress conditions. Results obtained in this study might suggest that sesquiterpenes are probably replaced by monoterpenes when drought is prolonged, because drought could impede cyclization of sesquiterpene precursors. In a similar way, it has been observed that cyclic monoterpenes were replaced by acyclic monoterpenes under restricted conditions of light and temperature (Staudt and Bertin, 1998) or humidity (Loreto et al., 1996).

While this study demonstrates that sesquiterpene emissions are reduced or inhibited when water resources in plants are scarce, sesquiterpene emissions are triggered when plants are exposed to other abiotic stresses, such as $\mathrm{O}_{3}$ (Beauchamp et al., 2005), light (Maes and Debergh, 2003), and temperature (Ibrahim et al., 2006). These studies provide evidence that the release of sesquiterpenes from leaves is a mechanism through which plants cope with the oxidative burst, which is one of the manifestations of the unfavourable action of these abiotic factors. Thus, in the light of the results obtained here, sesquiterpene emissions would only be emitted from leaves as antioxidant compounds, under relatively mild water stress conditions, while only monoterpenes would provide an additional barrier to plant damage during severe lack of water resources. Their different response to drought could be linked to the fact that (i) these isoprenoids have different physicochemical characteristics (Niinemets et al., 2004) (ii) monoterpenes are synthesized through the plastidic non-mevalonate, methylerythritol-phosphate (MEP) pathway, while sesquiterpenes are mainly synthesized through the cytosolic mevalonate (MVA) pathway (Umlauf et al., 2004).

\section{Conclusion}

Two major ecological conclusions can be inferred from the fact that only leaf monoterpene emissions may be favoured or maintained against prolonged water withholding periods. Firstly, monoterpenes, rather than sesquiterpenes, seem to protect plants against severe drought periods. Secondly, since the total rainfall in the Mediterranean Basin is expected to decline drastically (Chou, 2005), this could lead plants to reduce the diversity of carbon based secondary metabolites produced, probably disfavouring plant defence.

In addition, since sesquiterpene emissions are considered to be mainly involved in aerosol formation, which may contribute to negative precipitation anomalies at a local scale (Chou, 2005), this could explain why plants drastically stop sesquiterpene release under severe drought conditions.

This study also suggests that terpene emissions could have a dramatic impact on the global terrestrial reactive carbon balance, since monoterpene decline only occurred under drought conditions which are in the range of severity observed in plants growing under Mediterranean summer conditions. Under these conditions, $\psi$ can drop below $-6 \mathrm{MPa}$ (Werner et al., 1999). However, it should be kept in mind that emissions related to surface of leaves will be smaller, since drought limits plant growth (Turtola et al., 2003). In any case, taking into account water stress as an input in models constructed to estimate terpene emissions from plants could be of great interest for a better understanding of tropospheric chemistry. For this purpose, the present study shows that plant water potential may be an efficient parameter for estimating emission changes according to water loss.

\section{Acknowledgements}

This research was primarily supported by the French Agriculture Minister (DERF: département de l'espace rural et de la forret), the Environmental agency (ADEME) and the PACA (Povence-Alpes-Côtes d'Azur) regional council. We are grateful to Assistant Prof. Christine Ballini for her technical assistance for plant water status measurements. We thank Mr. Michael Paul for improvements to the English.

\section{References}

Arey, J., Crowley, D.E., Crowley, M., Resketo, M., Lester, J., 1995. Hydrocarbon emissions from natural vegetation in california southcoast-air-basin. Atmos. Environ. 29, 2977-2988.

Argiller, C., Falconnet, G., Gruez, J., 1991. Production de plants forestiers. In: CEMAGREF (Eds.), Guide technique du forestier méditerranéen français., Aix-en-Provence, p. 40 (Chapter 6).

Beauchamp, J., Wisthaler, A., Hansel, A., Kleist, E., Miebach, M., Niinemets, U., Schurr, U., Wildt, J., 2005. Ozone induced emissions of biogenic VOC from tobacco: relationships between ozone uptake and emission of LOX products. Plant Cell Environ. 28, 1334-1343.

Bertin, N., Staudt, M., 1996. Effect of water stress on monoterpene emissions from young potted holm oak (Quercus ilex L) trees. Oecologia 107, 456-462.

Bryan, J., Chapin III, F.S., Klein, D., 1983. Carbon/nutrient balance of boreal plants in relation to vertebrate herbivory. Oikos 40.

Chou, C., 2005. Local and remote impacts of aerosol climate forcing on tropical precipitation. J. Climate 18, 4621-4636.

Delfine, S., Loreto, F., Pinelli, P., Tognetti, R., Alvino, A., 2005. Isoprenoids content and photosynthetic limitations in rosemary and spearmint plants under water stress. Agr. Ecosyst. Environ. 106, 243 252. 
Funk, J.L., Mak, J.E., Lerdau, M.T., 2004. Stress-induced changes in carbon sources for isoprene production in Populus deltoides. Plant Cell Environ. 27, 747-755.

Guenther, A., 2002. The contribution of reactive carbon emissions from vegetation to the carbon balance of terrestrial ecosystems. Chemosphere 49, 837-844.

Guenther, A., Hewitt, C.N., Erickson, D., Fall, R., Geron, C., Graedel, T., Harley, P., Klinger, L., Lerdau, M., Mckay, W.A., Pierce, T., Scholes, B., Steinbrecher, R., Tallamraju, R., Taylor, J., Zimmerman, P., 1995. A global-model of natural volatile organic-compound emissions. J. Geophys. Res-Atmos. 100, 8873-8892.

Hansen, U., Seufert, G., 1999. Terpenoid emission from Citrus sinensis (L.) OSBECK under drought stress. Phys. Chem. Earth Pt B. 24, 681687.

Hansen, U., Van Eijk, J., Bertin, N., Staudt, M., Kotzias, D., Seufert, G., Fugit, J.L., Torres, L., Cecinato, A., Brancaleoni, E., Ciccioli, P., Bomboi, T., 1997. Biogenic emissions and $\mathrm{CO}_{2}$ gas exchange investigated on four Mediterranean shrubs. Atmos. Environ. 31, 157-166.

Ibrahim, M.A., Nissinen, A., Prozherina, N., Oksanen, E.J., Holopainen, J.K., 2006. The influence of exogenous monoterpene treatment and elevated temperature on growth, physiology, chemical content and headspace volatiles of two carrot cultivars (Daucus carota L.). Environ. Exp. Bot. 56, 95-107.

Inclan, R., Alonso, R., Pujadas, M., Teres, J., Gimeno, B.S., 1998. Ozone and drought stress: interactive effects on gas exchange in Aleppo pine (Pinus halepensis Mill.). Chemosphere 36, 685-690.

Kattenburg, A., Giorgi, F., Grassil, H., Meehl, G.A., Mitchell, J.F.B., Stouffer, R.J., Tokioka, T., Weaver, A.J., and Wigley, T.M.L., 1996. Climate-models-projections of future climate. Climate change $1995-$ the science of climate change. Contribution working group I of the second assessment report of the intergovernmental panel of climate change. Cambridge University Press, Cambridge, UK, pp. 285-357.

Llusià, J., Peñuelas, J., 1998. Changes in terpene content and emission in potted Mediterranean woody plants under severe drought. Can. J. Bot. 76, 1366-1373.

Llusià, J., Peñuelas, J., 2000. Seasonal patterns of terpene content and emission from seven Mediterranean woody species in field conditions. Am. J. Bot. 87, 133-140.

Loreto, F., Ciccioli, P., Brancaleoni, E., Cecinato, A., Frattoni, M., Sharkey, T.D., 1996. Different sources of reduced carbon contribute to form three classes of terpenoid emitted by Quercus ilex L leaves. P. Natl. Acad. Sci. USA 93, 9966-9969.

Lorio, P.L., 1986. Growth-differentiation balance - a basis for understanding southern pine-beetle tree interactions. Forest Ecol. Manag. $14,259-273$.

Maes, K., Debergh, P.C., 2003. Volatiles emitted from in vitro grown tomato shoots during abiotic and biotic stress. Plant Cell Tiss. Org. 75, $73-78$.

Niinemets, U., Hauff, K., Bertin, N., Tenhunen, J.D., Steinbrecher, R., Seufert, G., 2002. Monoterpene emissions in relation to foliar photosynthetic and structural variables in Mediterranean evergreen Quercus species. New Phytol. 153, 243-256.

Niinemets, U., Loreto, F., Reichstein, M., 2004. Physiological and physicochemical controls on foliar volatile organic compound emissions. Trends Plant Sci. 9, 180-186.
Pegoraro, E., Rey, A., Greenberg, J., Harley, P., Grace, J., Malhi, Y., Guenther, A., 2004. Effect of drought on isoprene emission rates from leaves of Quercus virginiana Mill. Atmos. Environ. 38, 6149-6156.

Peñuelas, J., Llusià, J., 1997. Effects of carbon dioxide, water supply, and seasonality on terpene content and emission by Rosmarinus officinalis. J. Chem. Ecol. 23, 979-993.

Sabillon, D., Cremades, L.V., 2001. Diurnal and seasonal variation of monoterpene emission rates for two typical Mediterranean species (Pinus pinea and Quercus ilex) from field measurements-relationship with temperature and PAR. Atmos. Environ. 35, 4419-4431.

Schmid, C., Steinbrecher, R., Ziegler, H., 1992. Partition coefficients of plant cuticles for monoterpenes. Trees 6, 32-36.

Sharkey, T.D., Loreto, F., 1993. Water stress, temperature, and light effects on the capacity for isoprene emission and photosynthesis of kudzu leaves. Oecologia 95, 328-333.

Simon, V., Dumergues, L., Solignac, G., Torres, L., 2005. Biogenic emissions from Pinus halepensis: a typical species of the Mediterranean area. Atmos. Environ. 74, 37-48.

Staudt, M., Bertin, N., 1998. Light and temperature dependence of the emission of cyclic and acyclic monoterpenes from holm oak (Quercus ilex L.) leaves. Plant Cell Environ. 21, 385-395.

Staudt, M., Rambal, S., Joffre, R., Kesselmeier, J., 2002. Impact of drought on seasonal monoterpene emissions from Quercus ilex in southern France. Agric.-Biol. Environ. Sci. 107, 722-730.

Tholl, D., Boland, W., Hansel, A., Loreto, F., Röse, U.S.R., Schnitzler, J.-P., 2006. Practical approaches to plant volatile analysis. The Plant J. $45,540-560$.

Tingey, D.T., Manning, M., Grothaus, L.C., Burns, W.F., 1980. Influence of light and temperature on monoterpene emission rates from slash pine. Plant Physiol. 65, 797-807.

Tsigaridis, K., Kanakidou, M., 2002. Importance of volatile organic compounds photochemistry over a forested area in central Greece. Atmos. Environ. 36, 3137-3146.

Turtola, S., Manninen, A.M., Rikala, R., Kainulainen, P., 2003. Drought stress alters the concentration of wood terpenoids in Scots pine and Norway spruce seedlings. J. Chem. Ecol. 29, 1981-1995.

Umlauf, D., Zapp, J., Becker, H., Adam, K.P., 2004. Biosynthesis of the irregular monoterpene artemisia ketone, the sesquiterpene germacrene $\mathrm{D}$ and other isoprenoids in Tanacetum vulgare L. (Asteraceae). Phytochemistry 65, 2463-2470.

Vallat, A., Gu, H.N., Dorn, S., 2005. How rainfall, relative humidity and temperature influence volatile emissions from apple trees in situ. Phytochemistry 66, 1540-1550.

Vilagrosa, A., Bellot, J., Vallejo, V.R., Gil-Pelegrin, E., 2003. Cavitation, stomatal conductance, and leaf dieback in seedlings of two cooccurring Mediterranean shrubs during an intense drought. J. Exp. Bot. 54, 2015-2024.

Werner, C., Correia, O., Wolfram, B., 1999. Two different strategies of Mediterranean macchia plants to avoid photoinhibitory damage by excessive radiation levels during summer drought. Acta Oecol. 20, 1523

Yani, A., Pauly, G., Faye, M., Salin, F., Gleizes, M., 1993. The effect of a long-term water-stress on the metabolism and emission of terpenes of the foliage of Cupressus-Sempervirens. Plant Cell Environ. 16, 975981. 